\title{
Virus-Induced Cancers in Africa: Epidemiology and Carcinogenesis Mechanisms
}

\author{
D. Moukassa1,2*, A. M. Boumba',2, C. F. Ngatali ${ }^{3}$, A. Ebatetou ${ }^{2}$, J. B. Nkoua Mbon ${ }^{4}$, J.-R. Ibara ${ }^{1,5}$ \\ ${ }^{1}$ Département de santé et biologie humaine, Faculté des sciences de la santé, Université Marien N'gouabi, Brazzaville, Congo \\ ${ }^{2}$ Laboratoire d'analyses médicales et morphologiques, Hôpital général de Loandjili, Pointe-Noire, Congo \\ ${ }^{3}$ Service de cancérologie et médecine interne, Hôpital général de Loandjili, Pointe-Noire, Congo \\ ${ }^{4}$ Service de carcinologie et radiothérapie, CHU de Brazzaville, Congo \\ ${ }^{5}$ Service de gastro-entérologie et médecine interne, CHU de Brazzaville, Congo \\ Email: ${ }^{\star}$ donatienmoukassa@gmail.com
}

How to cite this paper: Moukassa, D., Boumba, A.M., Ngatali, C.F., Ebatetou, A., Nkoua Mbon, J.B. and Ibara, J.-R. (2018) Virus-Induced Cancers in Africa: Epidemiology and Carcinogenesis Mechanisms. Open Journal of Pathology, 8, 1-14.

https://doi.org/10.4236/ojpathology.2018.8 1001

Received: October 21, 2018

Accepted: November 21, 2018

Published: November 24, 2018

Copyright $(9) 2018$ by authors and Scientific Research Publishing Inc. This work is licensed under the Creative Commons Attribution International License (CC BY 4.0).

http://creativecommons.org/licenses/by/4.0/

\begin{abstract}
The resurgence of infectious diseases on the African continent plays a major role in the increase in cancer occurrence. Whereas in developed countries the causes of occurrence of cancers are related mainly to non-infectious factors; cancers of infectious origin become a dramatic particularity in Africa. The proportion of virus-induced cancers may reach up to $75 \%$ of cancer cases in certain countries. Oncogenic viruses such as human papilloma virus (HPV), hepatitis viruses $B$ and $C$, human herpes virus 8 and Epstein Barr virus in association with human immunodeficiency virus are the main viral etiologies of cancers in Africa, representing around 30\% of cancers causes. Optimistically, 30\% of cancers could be prevented in Africa. However, health burden prevails on the continent due to the weakness of health policy especially regarding preventive medicine, but also the limited technical facilities, poor manpower and insufficient political commitment. We felt urgent to review the state of the art of the question, and necessary to analyze and publicize the current epidemiological advances in oncogenic viruses and virus-induced cancers in Africa. Prevention implies understanding, which is compulsory to reverse the current trends and to potentially instate a control of virus-induced cancers.
\end{abstract}

\section{Keywords}

Virus-Induced Cancers, Infectious Diseases, Tumor Viruses, Africa

\section{Introduction}

Despite considerable advances in detection, treatment and prevention, cancer remains a major worldwide burden as it is the first cause of death in developed 
countries and the second in developing countries [1]. In 2008, the World Health Organization (WHO) gave the estimate of 12.7 million new cases of cancer worldwide with 7.6 million deaths (nearly 13\% of global mortality). Approximately $70 \%$ of cases occurred in southern countries [2] [3]. Estimates for 2030 and 2050 indicate that mortality may respectively exceed 13.1 and 17.5 million deaths for 22 and 27 million new cases worldwide of which $95 \%$ will occur in southern countries [1] [4]. These very clear differences in incidence and mortality reflect differences in exposure to determinant risk factors such as infectious diseases, e.g., in Africa. In 2008 also, other statistics showed that 2 million new cancer cases (16.1\%) worldwide are caused by infectious diseases of which approximately $33 \%$ occurred in sub-Saharan Africa. Bacteria (Helicobacter pylori-associated gastric cancer), parasites (Schistosoma haematobium-associated bladder cancer) and viruses were the main causative etiology [5].

Epidemiological and molecular studies have identified eight viruses that induce or promote cancer occurrence in humans: hepatitis B (HBV) and C (HCV) viruses, Epstein-Barr virus (EBV), human papillomavirus (HPV), human T lymphotropic virus type 1(HTLV-1), human herpes virus 8 (HHV8), Kaposi's sarcoma herpes virus-8 (KSHV-8), and also human immunodeficiency virus (HIV1 and 2). These viruses are often found in coinfection [6] [7].

Viral involvement in cancer occurrence in Africa may represent an opportunity, as it reflects a hope to significantly reduce cancer incidence and mortality through prevention and/or treatment of viral infections. Our purpose was therefore to review recent advances in epidemiological and control aspects of virus-induced cancers, as well as the molecular biology of viral carcinogenesis in the particular context of the African continent.

\section{Methodology}

A thorough literature search was undertaken to dig-up and review recent articles from the PubMed database (National Library of Medicine-National Institutes of Health) using the following key words: "transforming virus", "persistent infection", "cancer in Africa", "viruses and cancer", "cancer epidemiology", "molecular basis of cancer". Using access codes, articles in both French and English in relation to our thematic were selected from Science Direct and Springer Link. Data presented at international conferences and published in abstract form were also of interest. Finally, articles published in "Médecine tropicale" and "Médecine d'Afrique Noire" were also analyzed and integrated in our database. Useful information from all items was summarized.

\section{Burden of Cancer in Africa: Epidemiological Background}

Sub-Saharan Africa is heavily affected by the continuous expansion of cancer with an annual incidence varying from 100 to 120 per 100,000 people. Mortality rates from cancer reach 75\% depending on cancer type and country of concern [7] [8]. In 2008, the number of deaths due to cancer in Africa stood at 512,402 (63\%) 
deaths [8]. WHO's projections (Figure 1) expect that by 2030 between 700,000 and 1.6 million new cases of cancer will be recorded and 500,000 to 1.2 million deaths (20\% of the impact on the continent). [9] Prostate and liver cancers, and Kaposi's sarcoma are the most frequently diagnosed in men while women suffer more often from breast cancer, uterine cervical cancer and liver cancer [7] [9]. National cancer registries of most African countries cover only $8.3 \%$ of cases, which certainly underestimates actual figures [10] [11]. The alleged causes of the severity of this situation in Africa are multiple and can be summarized as follows: late access to care and drugs; poverty and weakness of infrastructure technical patient care facilities, especially regarding the use of specific high cost diagnosis and treatment; lack of skills of health workers; and lack of political drive [8] [11].

Despite the commitment by African countries to allocate 15\% of their Gross Domestic Product (GDP) to health improvement in 2001 (Declaration of Abuja, Nigeria), only four out of 53 countries have reached the target set in 2008 (Rwanda 18.9\%; Liberia, 16.8\%; Tanzania and Zambia $16.2 \%$ and $15.2 \%$, respectively) [12]. As a result, the economic consequences of cancer in Africa remain at a high estimate of 849 million USD in 2009 [13].

\section{Problem of Virus-Induced Human Cancers in Africa}

It is now recognized that many cancers have an infectious etiology [4]. Between $15 \%$ to $20 \%$ of human cancers worldwide are virus-induced. Approximately $80 \%$ of virus-induced cancer cases are represented by cervical cancer and hepatocellular carcinoma. In 2008, about $23 \%$ of cancers of infectious origin were recorded in developing countries compared to only $7.4 \%$ in developed countries. The situation was most critical in Sub-Saharan Africa, where infections were responsible of $32.7 \%$ of cases versus $3.3 \%$ in Oceania, as an example. The high prevalence of hepatitis B and C, HPV and HIV in cancers such as Kaposi's sarcoma does not improve the situation on the continent [11].

Virus-induced cancers represent a true African continents specificity, compared to cancers affecting developed countries that depend mainly on hormonal and genetic factors [14]. This particular etiological profile may be explained by several reasons other than weakness of health systems and lack of political will of Governors. Several armed conflicts ravage Africa, with immediate consequences such as

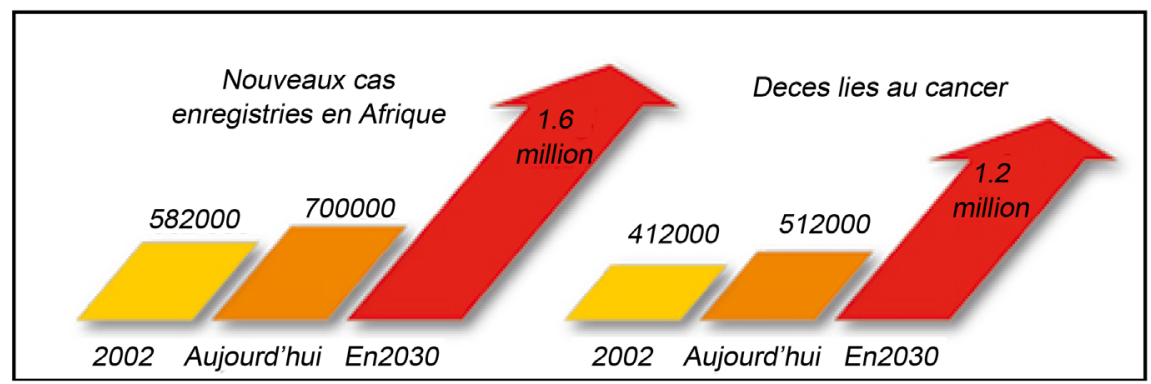

Figure 1. Estimated incidence and mortality of cancer in Africa (GLOBOCAN, 2008) (9). 
population displacement, promiscuity epidemics eased by the lack of drinking water and famine, sexual crimes with increased sexually transmitted infections (STIs), etc. Ward is organizes all organizational systems, including health systems, and creates favorable conditions for the development of infectious diseases that may trigger cancer in a longer term.

The economic consequences of cancers of infectious origin, especially virus-induced cancers, impose to take appropriate measures to control viral diseases across the continent. It is our belief that improving public awareness of virus-induced cancer pathology may also represent a major axis of prevention [15]. In terms of human development, the WHO study through the International Agency for Research on Cancer (IARC) stated: "the evolution of the cancer burden in the world is based on human development as it is (?) mainly affecting some countries social and economic transition, ...” [3].

\section{Viral Mechanism of Carcinogenesis}

Oncogenic DNA or RNA viruses are able to induce the formation of tumors. Transforming viral infections are still persistent, chronic, latent or abortive. The persistent viral genome integrates all or part of the DNA of the infected cell to persist as proviral form or remain in episomal form in the cytoplasm [16].

Although the mechanism of viral oncogenesis depends on the type of virus, certain physiological or metabolic pathways are common to all cancers. The process of initiation and development of virus-induced cancers is due to an accumulation of anomalies leading to immortalization and physiological and morphological alterations that define the state of transformation, i.e., the increased viability in a poorer growth factor environment, the locking mechanisms of apoptosis and senescence, the exhaustion of the immune system, etc. [17]. These modifications involve either the activation of genes that stimulate cell proliferation (viral or cellular oncogenes) or inactivation of genes that inhibit cell growth (tumor suppressor genes), but also those involved in DNA repair [17] [18].

In general, oncogenesis induced by RNA viruses is based on insertion of a viral activator near a cellular proto-oncogene (insertional mutagenesis), or integration into the cellular genome of a viral oncogene activated while oncogenesis induced DNA viruses. Such an integration is based either on the inactivation of a cellular anti-oncogene (tumor suppressor gene) as p53 or pRb, or on mutations, or even on the insertion of the virus genome at a critical point in the cellular genome. In some cases, the virus plays a prolonged role in the initiation of tumor in the persistence of the malignant phenotype [18].

\section{Tumor Viruses and Human Cancers Associated}

Among the families of known human tumor viruses, the following can be distinguished: Retroviridae and Flaviviridae for RNA viruses; Hepadnaviridae, Herpesviridae and Papillomaviridae for DNA tumor viruses (Table 1). 
Table 1. Oncogenic human viruses and tumors associated.

\begin{tabular}{cccc}
\hline Virus & Family & Virus & Tumors associated \\
\hline \multirow{2}{*}{ RNA } & Retroviridae & HTLV1 & Adult T leukemia, lymphoma \\
& Flaviviridae & HVC & Hepatocellular carcinoma \\
& Papillomaviridae & HPV-HR & $\begin{array}{c}\text { Papilloma, anogenital carcinomas, cancers of the } \\
\text { skin and upper respiratory tract }\end{array}$ \\
& Hepadnaviridae & HBV & Hepatocellular carcinoma \\
DNA & Herpesviridae & EBV & $\begin{array}{c}\text { Burkitt's lymphoma, nasopharyngeal carcinoma, } \\
\text { leiomyoma and leiomyosarcoma, lymphoma } \\
\text { immunoblastic, Hodgkin's disease? }\end{array}$ \\
& & HHV8 (KSHV) & Kaposi's sarcoma, B-cell lymphoma \\
\hline
\end{tabular}

HTLV1: human T-lymphotropic virus type I; HIV: human immunodeficiency virus; HCV: hepatitis C virus; HBV: hepatitis B virus; HPV-HR: high-risk human papillomavirus oncogen; EBV: Epstein-Barr virus; KSHV: herpesvirus associated with Kaposi's sarcoma; HHV8: human herpesvirus.

\subsection{Human Papillomavirus (HPV) and Cervical Cancer of the Uterus}

HPVs are small viruses from 52 to $55 \mathrm{~nm}$ in diameter, non-enveloped, doublestranded DNA, circular, approximately 8000 bp with an icosahedral capsid. The family has more than 200 known genotypes for nearly 120 characterized HPV [19]. Fifteen HPV oncogenes classified as high risk (HR-HPV) are responsible for most malignancies associated with cervical cancer of the uterus [20].

In terms of incidence and mortality, cervix cancers are respectively considered in 3rd and 4th class positions of all female cancers. Cervical cancers represent a global $9 \%(529,800)$ of all new cases and $8 \%(275,100)$ of all cancer deaths among women [21]. This low incidence results from the impact of efforts by Western countries for prevention, screening and treatment. However, the opposite curve is observed in southern countries where more than $85 \%$ of cases continue to be recorded. In Africa, cervical cancer remains the leading cause of death with 53.300 (19\%) deaths for an incidence of $80.400(21 \%)$ new cases, representing the second most common cancer among women in the continent. [22].

The occurrence of cervical cancer is the result of a persistent infection of HR-HPV which is the most common STI caused by a virus. Their transforming power is linked to the activity of viral proteins E6, E7 and E5 [23]. The mode of action of E6 and E7 is very complex. The E6 protein forms complexes with the p53 protein, through protein E6AP. This leads to ubiquitination of p53 degradation and thus a reduction of the genetic stability and accumulation of abnormal DNA cells expressing E6. The E7 protein binds to Rb protein family and no longer interacts with the proteinase inhibitor of cyclin-dependent kinases (p27/ p21). The interactions of E6 and E7 proteins with $\mathrm{p} 53$ and pRb make them inactive and unable to control cell proliferation and induce apoptosis in case of failure. Protein E5 exerts stimulatory activity on cell proliferation in a complementary manner with E7. The interference of these proteins with the immune system reduces the cytotoxic response and the response to interferon. Furthermore, the 
viral carcinogenesis HPV type also depends on the genetic background of the host [23].

\subsection{Hepatitis Viruses B and C (HBV and HCV) and Hepatocellular Carcinoma}

Viral hepatitis B virus presents the smallest human DNA genome with a 3,200 base pair double-stranded circular of $50 \%$ to $80 \%$ of its length. It encodes four genes: the $\mathrm{C}$ genes with a pre-core region (capsid or core) consisting of $\mathrm{HBC}$ antigen; the $\mathrm{S}$ genes, a zone with pre-S1 and pre-S2 (the envelope) consisting of $\mathrm{HBsAg}$ gene; $\mathrm{P}$ is for polymerase gene $\mathrm{X}$ transactivator, involved in virus carcinogenesis [24]. Hepatitis $\mathrm{C}$ virus is a wrapped flavivirus with a 30 to $60-\mathrm{nm}$ icosahedral capsid diameter. The genome is a positive single-stranded RNA of 9600 base pairs coding for ten proteins from a single reading frame [24]. Both viruses are involved in the onset of liver cancer, which represents the fifth most diagnosed cancer in men in the world, but the second global cause of death from cancer. In women, it occupies the 7th place and 6th leading cause of death. In 2008 , about 748,300 cases were recorded for 695,900 deaths worldwide, half being registered in China. [25] The highest rates are recorded in the less developed countries especially in Western Africa, while the lowest rates are found in Europe.

Of all cancers of the liver, hepatocellular carcinoma (HCC) is the most common histological type covering $70 \%-85 \%$ of the total liver cancer. Cholangiocarcinoma, although rare, is frequently observed in Thailand and East Asia [26]. The HCC is the third leading cause of death by cancer in the world with $77 \%$ of cases in developing countries (23\% in developed countries). In Africa, it is the second leading cause of cancer in men and the third in women. The high incidence in sub-Saharan Africa is related to chronic infection with $\mathrm{HBV}$ and HCV [26]. Around 5\% - 8\% of immunocompetent adults and 30\% to $40 \%$ of immunosuppressed people develop chronic infection with HBV. Figures can reach $90 \%$ of cases when HBV is contracted at birth with a risk of developing HCC equal to $50 \%$ in boys and $20 \%$ in girls. A prevalence rate of chronic carriage of HBsAg equals $8 \%$ in sub-Saharan Africa, $15 \%$ of patients developing HCC [7].

Carcinogenesis induced by HBV involves several mechanisms: insertional mutagenesis due to the partial integration of the virus into the DNA of liver cells. This leads to the activation of cellular proto-oncogenes C-myc, the action of different regulatory proteins of viral origin (pre-S, HBx) that stimulate many oncogenic promoters, and chronic inflammation causing death by hepatocyte apoptosis and increased cell regeneration promoting mutations. Protein $\mathrm{X}$ is known to activate the kinase src and can also interact with p53 [27]. For its part, HCV infection becomes chronic in $70 \%$ of patients, of whom $1 \%-5 \%$ develop HCC. It represents $33 \%$ of cases in developing countries versus $20 \%$ in developed countries. HCV replicates in the cytoplasm of hepatocytes and does not integrate into the cellular genome, which explains why its carcinogenetic power remains obscure. 
$\mathrm{HCV}$ intervenes directly in the process of hepatic carcinogenesis transactivation of some cellular oncogenes, deregulation of the control of apoptosis and, indirectly, in inflammation, necrosis and cell regeneration [28].

\subsection{Epstein-Barr Virus (EBV) and Burkitt's Lymphoma}

EBV or human herpes virus type 4 is a ubiquitous enveloped lymphotropic virus of the Gammaherpesvirinae subfamily. The genome is a linear double-stranded DNA from $175 \mathrm{~Kb}$ to icosahedral capsid coding for proteins $100-150$ divided into several unique domains separated by internal repeats 1 to 4 (IR Internal Repeats). In the world more than $95 \%$ of individuals are infected mainly through saliva before adulthood, although a small proportion develops mononucleosis. In sub-Saharan Africa, almost all children are infected from mother to child with EBV before the age of 5 years [29]. EBV is implicated in Burkitt's lymphoma (BL) that is endemic in Africa, in nasopharyngeal cancers, in Hodgkin's disease and non-Hodgkin lymphoma (NHL) in immunosuppressed patients (transplant, AIDS).

Burkitt's lymphoma is a NHL of the lymphatic system that targets on Blymphocytes within the germinal center of lymph nodes. It was described in 1957 by Denis Burkitt in Kampala (Uganda). It is characterized by the proliferation and deregulation of the c-myc gene [30]. It represents $35 \%$ to $50 \%$ of NHL in children and $2 \%$ of NHL in adults. Three main types are described: endemic BL, sporadic $\mathrm{BL}$ and BL associated with HIV infection [31]. In all three forms, the lymphoma cells are derived from B lymphocytes. It involves always one of the three translocations: $\mathrm{t}(8 ; 14)$ the most frequent $\mathrm{t}(2 ; 8)$ or $\mathrm{t}(8 ; 22)$, which are the $\mathrm{c}$-myc oncogene (chromosome 8 ) in dependence on the heavy (chromosome 14) or light chain gene (chromosome 2 or 22) of IgG, leading to hyper-expression of the oncogene c-myc. The proliferation of malignant clone is lymphoma [29]. The endemic form is a tumor of the jaws of African children with an incidence of 5 to 10 cases per 100,000 inhabitants. The endemicity of BL in Africa resultsfrom the initial infection (genome found in $98 \%$ of cases of endemic BL), as well as specific African conditions such as climate and malaria or HIV infections (30\% to $40 \%$ of patients have EBV) [29].

The transformation mechanism of the virus involves at least six viral proteins contributing to the immortalization of B cells. Among them, the transactivator EBNA2 (Nuclear Antigen associated with EBV), and LMP1 (Latent Membrane Protein 1) play a role in inducing the transcription of molecules involved in $B$ cell activation, or by deregulating mechanisms of cellular homeostasis [32]. The process of immortalization and transformation of very complex products involves several viral genes having the ability to maintain the virus in the infected cell and mimic the cellular signals involved in the growth of lymphoid cells cycle regulation or cell apoptosis [33]. T-cytotoxic response lacks control on the proliferation of infected cells and allows it to undergo further mutational events and to progress to lymphoma. 


\subsection{Human Herpesvirus 8 (HHV8) and Kaposi's Sarcoma}

Classified as EBV in the Gammaherpesvirinae subfamily, HHV8 is an enveloped virus of $110-150 \mathrm{~nm}$ in diameter with an icosahedral capsid discovered in 1994. The genome is a linear double-stranded DNA of about $170 \mathrm{~kb}$ composed of a long unique region of $140 \mathrm{~kb}$, which has nearly 90 genes with terminal repeat regions (TR) at both ends. The genome variability can differentiate five subtypes: subtypes $\mathrm{A}$ and $\mathrm{C}$ predominate in southern Europe and the Mediterranean basin; subtype $\mathrm{B}$ is present in sub-Saharan Africa; subtypes $\mathrm{D}$ and $\mathrm{E}$ are found respectively in the Pacific Islands and Japan, and also among South-American Indians [34]. The oncogenic potential of HHV8 is associated with latency proteins lanal (latency-associated nuclear antigen-1), cyclin $\mathrm{K}$ and vflip, although the role of other viral proteins (vGPCR, vIRF1, K1, kaposine A) has been demonstrated. The latency nuclear antigen (ADSL) is responsible for maintaining the viral episome, but also is a modulator of cellular transcription, capable of inhibiting apoptosis mediated by p53 or causing expression of a number of proteins (c-myc, etc.) [35]. The pathophysiology associates more genes involved in angiogenesis (MIP or homologues of IL-6), in the inhibition of the response to interferon, or in the inhibition of apoptosis (vbcl-2 and vflip). GPCR is a transforming gene that induces the synthesis of VEGF by the cell, giving it very important angiogenic potency. Finally, the homologue of the IL-6-induced proliferation of B lineage protects them from apoptosis [34].

HHV8 is the etiologic agent of Kaposi's sarcoma (KS), a malignancy of B lymphocytes that especially affects immunocompromised persons. It is a process of proliferative mesenchymal blood and lymphatic system cells, induced by growth factors such as viral IL-6 of HHV8. Four clinical forms are recognized: the classic Mediterranean sarcoma (described by Kaposi in 1872); the endemic form (described in 1950 in Central and East Africa), known as post-transplant (described in 1970 and related to acquired iatrogenic immunosuppression); and AIDS-related epidemic form (described in 1981, representing $20 \%$ to $50 \%$ of all cancers diagnosed) that has become the leading cause of death in men and the fourth among women in Africa [36].

African KS is endemic in areas with high incidence of malaria and BL. After a chronic course, death occurs 10 - 15 years after onset (15). Prevalence in Africa is very high, especially in Uganda and $57 \%$ of children are infected before the first sexual intercourse compared to $2 \%-5 \%$ in developed countries [37].

\subsection{HTLV-1 and Adult T Leukemia/Lymphoma (ATL)}

HTLV-1 is an exogenous oncogenic retrovirus $80-110 \mathrm{~nm}$ in diameter belonging to the Delta-retrovirus subfamily, identified in 1980 by Gallo (USA) [38]. The viral genome is a positive single-stranded RNA of 9000 bp present in two copies, flanked by two Long Terminal Repeats (LTR) between which lie the usual three genes of the family, Gag, Pol and Env, and pX gene that encodes for two regulatory proteins (Tax and Rex) involved in the oncogenic process [39]. 
Contrary to the mechanism of oncogenic retroviruses involving cis-activators or transducers, HTLV-1 has no viral oncogene similar to cellular proto-oncogene (v-onc) and is therefore not responsible for the malignant process. However, the Tax gene plays an important role in replication and cell transformation and is able to immortalize human $\mathrm{T}$ lymphocytes in cooperation with the ras oncogene. The inhibition of the promoter of $\beta$-cell polymerase (role in DNA repair) by the Tax protein promotes the early occurrence of cytogenetic abnormalities. The complexity of the transformation mechanism of HTLV-1 involves altering of either the expression (repression or activation of the promoter) or function (inactivation or modification by direct binding of the cellular protein) of several proteins that are involved in the control of cell cycle (p53, p21, cyclin D2, p16, cyclin D3), in the survival of the cell (Bax, Bcl-2, NF-kB, c-fos) or in the proliferation or activation of the cell (IL-2, IL-15, GM-CSF). The Rex protein on the other hand increases the expression of certain cellular messenger RNAs encoding such as the alpha chain of the receptor for IL-2 [40]. Recently, has been shown the important role of the HBZ protein in cell proliferation whose expression is maintained in the adult $\mathrm{T}$ leukemia/lymphoma (ATL). In the end, epigenetic dysregulation, such as methylation of promoters and miRNA deregulation has also been demonstrated in ATL [41].

Epidemiologically, the virus possesses a high genetic stability despite the existence of four major molecular variants according to the geographic area of occurrence: cosmopolitan subtype (A); subtype in Central Africa (B); Melanesian subtype (C); and pygmies of Central Africa subtype (D) [42]. Tropical Africa and Central Africa (Gabon, RDC) represent areas with high endemicity [38]. Clinically HTLV-1 causes two severe diseases: adult T leukemia/lymphoma and chronic myelopathy. The former ATL, an adult lymphoid malignancy, has been divided in three clinical forms: acute rapidly fatal forms, chronic form, and slowly progressive indolent "smoldering" form (5\%), which may progress to either acute or chronic form. Chronic myelopathy is characterized by spastic paraparesis (Tropical Spastic Paraparesis or Human Associated Myelopathy HTLV-1; TSP/HAM) which begins around 40 - 50 years. In the world, 15 to 25 million people are infected by HTLV-1, but only $3 \%$ - $6 \%$ develop ATL or TSP/ HAM [38].

\subsection{Human Immunodeficiency Virus (HIV1 and HIV2) and Associated Cancers}

HIV is a retrovirus belonging to the Lentivirinae subfamily. It is in the form of a spherical particle of from 90 to $120 \mathrm{~nm}$ in diameter bristling spicules. The genetic similarity is used to classify strains into types, groups and subtypes. There are two major types: HIV1 and HIV2 that have $42 \%$ genomic homology.

The viral genome consists of two identical single-stranded RNA molecules of $9181 \mathrm{bp}$ and has nine open reading frames. Three of these frames encode polyproteins Gag, Gag-Pol and Env, which are subsequently cleaved into individual proteins. The other six reading frames are: tat and rev genes that encode regulatory viral proteins essential for viral replication; genes nef, vif, vpr and vpu that 
encode proteins but remain accessories required for viral replication and pathogenesis in vivo. HIV2 has the vpu gene in place of the vpx gene [37].

The great variability of HIV is linked to nucleotide incorporation errors provoked by reverse transcriptase during reverse transcription of viral RNA into viral DNA. The error rate is associated with a dynamic high viral replication resulting in the accumulation of many viral variants. This variability provides the virus with a great adaptability and allows it to escape the immune system of the host. The HIV1 are classified into three groups, M, N and O. Group M viruses represent the vast majority of characterized isolates. Phylogenetic analysis distinguish currently ten subtypes, A to J, with a $20 \%$ to $30 \%$ difference in homology of the env gene [38].

In Africa, all subtypes of group M HIV-1 are present, with a very heterogeneous distribution and variability within subtypes. In the Great Lakes region, subtypes A and D are the most common. Subtype C prevails in Ethiopia and Southern Africa (together with subtype B). In West and Central Africa, while subtype A predominates, all other subtypes have been reported. In Cameroon, we found the highest prevalence of group O HIV-1 and early identification of group N HIV-1 isolate [38].

HIV is a global public health problem with more than 25 million deaths worldwide and at least 33 million people living with HIV as in 2007. Sub-Saharan Africa is the most affected region with over 1.9 million new infections in 2007, reaching about 22 million people living with HIV, i.e., two-thirds of global figures. Over $90 \%$ of children below 15 years of age infected with HIV died from AIDS-related illness in sub-Saharan Africa. In 2007, one third of all new HIV infections and of global AIDS fatalities resided in Southern Africa. In 2005, national prevalence exceeded $15 \%$ in adults living in eight countries (South Africa, Botswana, Lesotho, Mozambique, Namibia, Swaziland, Zambia and Zimbabwe) [40].

Infection with HIV belongs to the pathology group of acquired immunodeficiency syndrome (AIDS) that allows for opportunistic infections. Among such infections, the so-called cancer "ranking" AIDS are responsible for cancers observed in HIV seropositive patients. Kaposi's sarcoma (the most common tumors in patients infected in Africa), the primary central nervous system lymphoma (PCNSL), Burkitt's lymphoma and cervical cancer are all associated with oncogenic viruses [41] [42]. However, despite the decrease in the incidence of non-Hodgkin lymphoma and Kaposi's sarcoma due to highly active antiretroviral therapy (HAART), the incidence of viral infections on virus-induced cancers remains largely increased (by at least a factor 20) compared to the general population [42]. In addition, an increased risk of developing other "non-AIDS-defining" cancers is not negligible in the lung, liver, and Hodgkin's disease [42].

\section{Conclusion}

Virus-induced cancers should be regarded as a public health problem in sub-Saharan Africa. The epidemic situation relative to these diseases reflects the magnitude of 
the weaknesses of health systems in the African continent. But also, antiviral treatment may be less effective than in other infectious diseases. However, we believe that anticipating viral infections will help controlling the burden of cancer in Africa. Prevention of viral infections with vaccine or therapeutic approaches represents one efficient lever on which African health authorities should pay large efforts. But there are other ways to prevention, regarding research for better understanding and knowledge of predisposing factors in Africa. Studies on all infectious diseases that can cause or increase the risk of cancer induction should be promoted in specific African research facilities to develop new and adapted techniques for diagnosis and treatment. Besides the building environment, such a policy requires qualified staff and adequate financial resources allocated to both basic and clinical research, as well as resources for teaching and formation for a more efficient capacity building in Africa itself. But there are again other ways to prevention regarding African public information and awareness for adapted hygiene measures on goods and certain risk behaviors related to feeding and eating habits and sexual behavior. The framework of cooperation and transfer of knowledge between countries of the South should be amplified in order to launch a dynamic over the continent. This constitutes another major capital lever to specifically control virus-induced cancers in Africa.

\section{Acknowledgements}

We sincerely thank Pr Alain Buguet (Malaria Research Unit, Claud-Bernard Lyon I University) for his critical reading and wise counselling in carrying out this article.

\section{Conflict of Competence}

The authors declare that they have no conflict of competence or interest.

\section{References}

[1] Garcia, M., Jemal, A., Ward, E.M., Center, M.M., Hao, Y., Siegel, R.L. and Thun, M.J. (2007) Global Cancer Facts \& Figures 2007. American Cancer Society, Atlanta.

[2] Ferlay, J., Shin, H.R., Bray, F., Forman, D., Mathers, C. and Parkin, D.M. (2010) GLOBOCAN 2008 v1.2, Cancer Incidence and Mortality Worldwide: IARC Cancer Base No. 10. International Agency for Research on Cancer, Lyon. http://globocan.iarc.fr

[3] Bray, F., Jemal, A., Grey, N., Ferlay, J. and Forman, D. (2012) Global Cancer Transitions According to the Human Development Index (2008-2030): A Population-Based Study. The Lancet Oncology, 13, 790-801. http://Thelancet.com/search/results https://doi.org/10.1016/S1470-2045(12)70211-5

[4] Lopez, A.D., Mathers, C.O., Ezzati, M., et al. (2006) Global and Regional Burden of Disease and Risk Factors, 2001: Systematic Analysis of Population Health Data. Lancet, 367, 1747-1757. https://doi.org/10.1016/S0140-6736(06)68770-9

[5] De Martel, C., Ferlay, J., Franceschi, S., Vignat, J., Bray, F., Forman, D. and Plummer, M. (2012) Global Burden of Cancers Attributable to Infections in 2008: A Review and Synthetic Analysis. Lancet Oncology, 13, 607-615 
http://www.thelancet.com/journals/lanonc/article/PIIS1470-2045(12)70176-6/fulltext https://doi.org/10.1016/S1470-2045(12)70137-7

[6] Bouvard, V., Baan, R., Straif, K., et al. (2009) On Behalf of the WHO International Agency for Research on Cancer Monograph Working Group. Special Report: Policy. A Review of Human Carcinogens-Part B: Biological Agents. Lancet Oncology, 10, 321-322. https://doi.org/10.1016/S1470-2045(09)70096-8

[7] Ly, A. (2011) Progression des cancers en Afrique: caractéristiques, altérité, nouvelles approches de santé publique. [Cancer Progression in Africa: Characteristics, Otherness, New Approaches to Public Health.] In: Kerouedan, D., Ed., Santé internationale. Les enjeux de santé au Sud, Sciences Po Presses, Paris, 121-140.

[8] Ly, A. (2011) Enjeux et perspectives de la prévention des cancers dans les pays en développement. [Current Issues and Future Prospects in Cancer Prevention in Developing Countries.] Journal Africain du Cancer, 3, 268-272.

https://doi.org/10.1007/s12558-011-0178-5

[9] Ferlay, J., Shin, H.R., Bray, F., Forman, D., Mathers, C. and Parkin, D.M. (2010) Estimates of Worldwide Burden of Cancer in 2008: GLOBOCAN 2008. International Journal of Cancer, 127, 2893-2917. https://doi.org/10.1002/ijc.25516

[10] Ly, A. (2008) Cancer en Afrique: défis et perspectives. [Cancer in Africa: Challenges and Prospects.] ReMeD, 38, 1-24.

[11] Ly, M., Ly, A., Rodrigues, M., Loriot, Y., Deberne, M., Boudou-Rouquette, P., Bathily, T. and Diallo, D. (2010) Le cancer en Afrique, un nouveau défi sanitaire. Exemples du Mali et de l'association OncoMali. [Cancer in Africa, a New Health Challenge. Examples from Mali and the OncoMali Association.] Bulletin du Cancer, 97, 965-968.

[12] Guerin, S. and Hill, C. (2010) L'épidémiologie des cancers en France en 2010: Comparaison avec les États-Unis. [The Epidemiology of Cancers in France in 2010: A Comparison with the United States.] Bulletin du Cancer, 97, 47-54.

[13] Dangou, J.M., Sambo, B.H., Moeti, M., Diarra Nama, A.J. (2009) Prévention et lutte contre le cancer dans la région Afrique de L'OMS: un appel à l'action. [Cancer Prevention and Control in the African Region: A Call to Action.] Journal Africain du Cancer, 1, 56-60. https://doi.org/10.1007/s12558-008-0008-6

[14] Maréchal, V. and Piolot, T. (1999) Oncogenesis and Biological Cycles of Viruses. Virologie, 3, 297-308.

[15] Newton, R., Beral, V. and Weiss, R.A., Eds. (1999) Cancer Surveys. Infections and Human Cancer. Imperial Cancer Research Fund, 33, 396.

[16] Antoine Gessain, et al. (2000) Notion de causalité virus-cancer chez l'homme Med. [Concept of Virus-Cancer Causality in Humans.] Thérap, 6, 826-836.

[17] Secondy, M. (2008) Classification des papillomavirus (HPV). [Classification of Human Papillomavirus (HPV).] Revue Francophone des Laboratoires, 405, 23-25. https://doi.org/10.1016/S1773-035X(08)74274-6

[18] Muñoz, N., Castellsague, X., de Gonzalez, A.B. and Gissmann, L. (2006) Chapter 1: HPV in the Etiology of Human Cancer. Vaccine, 24, S1-S10. https://doi.org/10.1016/j.vaccine.2006.05.115

[19] Jemal, A., Bray, F., Center, M.M., Ferlay, J., Ward, E. and Forman, D. (2011) Global Cancer Statistics. CA: A Cancer Journal for Clinicians, 61, 69-90. https://doi.org/10.3322/caac.20107

[20] Yugawa, T. and Kiyono, T. (2009) Molecular Mechanisms of Cervical Carcinogenesis by High-Risk Human Papillomaviruses: Novel Functions of E6 and E7 Onco- 
proteins. Reviews in Medical Virology, 19, 97-113.

https://doi.org/10.1002/rmv.605

[21] Perz, J.F., Armstrong, G.L., Farrington, L.A., et al. (2006) The Contributions of Hepatitis B Virus and Hepatitis C Virus Infections to Cirrhosis and Primary Liver Cancer Worldwide. Journal of Hepatology, 45, 529-538.

https://doi.org/10.1016/j.jhep.2006.05.013

[22] René Lambert (2009) Dossier Thématique: Cancer Du Foie Et Des Voies Biliaires (I.A.R.C) Épidémiologie du carcinome hépatocellulaire ( $\mathrm{CHC}$ ) dans le monde Cancéro dig. [Thematic File: Cancer of the Liver and Bile Ducts: Epidemiology of Hepatocellular Carcinoma (HCC) in the World.] Vol. 1, 86-90.

[23] Raza, S.A., Clifford, G.M. and Franceschi, S. (2007) Worldwide Variation in the Relative Importance of Hepatitis B and Hepatitis C Viruses in Hepatocellular Carcinoma: A Systematic Review. British Journal of Cancer, 96, 1127-1134. https://doi.org/10.1038/sj.bjc.6603649

[24] Germi, R., Baccard, M., Seigneurin, J.M. and Morand, P. (2011) Infections à virus Epstein-Barr. [Epstein-Barr Virus Infections.] EMC (Elsevier Masson, Paris), Infectious Diseases, 8-070-k-10.

[25] Ferry Judith, A. (2006) Burkitt's Lymphoma: Clinicopathologic Features and Differential Diagnosis. The Oncologist, 11, 375-383.

https://doi.org/10.1634/theoncologist.11-4-375

[26] Raphaël, M. and Poirel, H.A. (2001) Virus Epstein-Barr et proliférations lymphoïdes B. [Epstein-Barr Virus and Lymphoid Proliferations B.] Revue Française des Laboratoires, 337, 59-63.

[27] McLaughlin-Drubin, M.E. and Munger, K. (2007) Viruses Associated with Human Cancer. Biochimica et Biophysica Acta, 1782, 127-150. https://doi.org/10.1016/j.bbadis.2007.12.005

[28] Boulanger, E. and Gessain, A. (2006) Herpèsvirus humain 8: Bases moléculaires de l'oncogenèse et de la modulation de la réponse immunitaire. [Human Herpesvirus 8: Molecular Basis of Oncogenesis and Modulation of the Immune Response.] Virologie, 10, 369-382.

[29] Morand, J.J., Lightburn, E., Simon, F. and Potte, J.H. (2007) Actualités sur la Maladie de Kaposi. [News about Kaposi's Disease.] Medecine Tropicale, 67, 123-130.

[30] Serraino, D., De Paoli, A., Zucchetto, A., Pennazza, S., Bruzzone, S., Spina, M., De Paoli, P., Rezza, G., Dal Maso, L. and Suligoi, B. (2010) The Impact of Kaposi Sarcoma and Non-Hodgkin Lymphoma on Mortality of People with AIDS in the Highly Active Antiretroviral Therapies Era. Cancer Epidemiology, 34, 257-261. https://doi.org/10.1016/j.canep.2010.03.011

[31] Gessain, A. (2005) Virus et lymphomes chez l'homme. Aspects épidémiologiques. [Viruses and Lymphomas in Humans: Epidemiological Aspects.] Revue Française des Laboratoires, 369, 36-40.

[32] Proietti, F.A., Carneiro-Proietti, A.B., Catalan-Soares, B.C. and Murphy, E.L. (2005) Global Epidemiology of HTLV-I Infection and Associated Diseases. Oncogene, 24, 6058-6068. https://doi.org/10.1038/sj.onc. 1208968

[33] Gessain, A. (2011) Le rétrovirus humain oncogène HTLV-1: Epidémiologie descriptive et moléculaire, origine, évolution et aspects diagnostiques et maladies associées. [HTLV-1 Oncogenic Human Retrovirus: Descriptive and Molecular Epidemiology, Origin, Evolution, and Diagnostic Aspects and Associated Diseases.] Bulletin De La Societe De Pathologie Exotique, 104, 167-180.

https://doi.org/10.1007/s13149-011-0174-4 
[34] Matsuoka, M. and Jeang, K.T. (2007) Human T-Cell Leukaemia Virus Type 1 (HTLV-1) Infectivity and Cellular Transformation. Nature Reviews Cancer, 7, 270-280. https://doi.org/10.1038/nrc2111

[35] Barbeau, B. and Mesnard, J.M. (2007) Does the HBZ Gene Represent a New Potential Target for the Treatment of Adult T-Cell Leukemia? International Reviews of Immunology, 26, 283-304. https://doi.org/10.1080/08830180701690843

[36] Gessian, A., Yanagihara, R., Franchini, G., Garruto, R.M., Jenkins, C.L., Ajdukiewicz, A.B., Gallo, R.C. and Gajdusek, D.C. (1991) Highly Divergent Molecularvariants of Human T-Lymphotropic Virus Type I from Isolated Populations in Papua New Guinea and the Solomon Islands. Proceedings of the National Academy of Sciences, 88, 7694-7698.

https://doi.org/10.1073/pnas.88.17.7694

[37] Plantier, J.C., Leoz, M., Dickerson, J.E., De Oliveira, F., Cordonnier, F., Lemee, V., Damond, F., Robertson, D.L. and Simon, F. (2009) A New Human Immunodeficiency Virus Derived from Gorillas. Nature Medicine, 15, 871-872. https://doi.org/10.1038/nm.2016

[38] Taylor, B.S. and Hammer, S.M. (2008) The Challenge of HIV-1 Subtype Diversity. The New England Journal of Medicine, 359, 1965-1966. https://doi.org/10.1056/NEJMc086373

[39] Sasco, A.J., Jaquet, A., Boidin, E., Ekouevi, D.K., Thouillot, F., Lemabec, T., Forstin, M.A., Renaudier, P., N'dom, P., Malvy, D. and Dabis, F. (2010) The Challenge of AIDS-Related Malignancies in Sub-Saharan Africa. PLoS ONE, 5, e8621. https://doi.org/10.1371/journal.pone.0008621

[40] ONUSIDA (2008) Le rapport sur l'épidémie mondiale de SIDA. [The Report on the Global AIDS Epidemic.] http://www.unaids.org/fr/dataanalysis/knowyourepidemic/

[41] Shiels, M.S., Pfeiffer, R.M., Gail, M.H., Hall, H.I., Li, J., Chaturvedi, A.K., Bhatia, K., Uldrick, T.S., Yarchoan, R., Goedert, J.J. and Engels, E.A. (2011) Cancer Burden in the HIV-Affected Population in the United States. JNCI: Journal of the National Cancer Institute, 103, 753-762. https://doi.org/10.1093/jnci/djr076

[42] Casper, C. (2011) The Increasing Burden of HIV-Associated Malignancies in Resource-Limited Regions. Annual Review of Medicine, 62, 157-170.

https://doi.org/10.1146/annurev-med-050409-103711 